\title{
Article
}

\section{The Effect of Organic and Conventional Cultivations on Antioxidants Content in Blackcurrant (Ribes nigrum L.) Species}

\author{
Joanna Rachtan-Janicka * ${ }^{\mathbb{D}}$, Alicja Ponder (D) and Ewelina Hallmann (iD \\ Department of Functional and Organic Food, Institute of Human Nutrition Sciences, \\ Warsaw University of Life Sciences, Nowoursynowska 159c, 02-776 Warsaw, Poland; \\ alicja_ponder@sggw.edu.pl (A.P.); ewelina_hallmann@sggw.edu.pl (E.H.) \\ * Correspondence: joanna_rachtan_janicka@sggw.edu.pl; Tel.: +48-22-59-370-45
}

Citation: Rachtan-Janicka, J.; Ponder,

A.; Hallmann, E. The Effect of

Organic and Conventional

Cultivations on Antioxidants Content in Blackcurrant (Ribes nigrum L.) Species. Appl. Sci. 2021, 11, 5113. https://doi.org/10.3390/ app11115113

Academic Editor: Monica Gallo

Received: 10 May 2021

Accepted: 25 May 2021

Published: 31 May 2021

Publisher's Note: MDPI stays neutral with regard to jurisdictional claims in published maps and institutional affiliations.

Copyright: (c) 2021 by the authors. Licensee MDPI, Basel, Switzerland. This article is an open access article distributed under the terms and conditions of the Creative Commons Attribution (CC BY) license (https:/ / creativecommons.org/licenses/by/ $4.0 /)$.

\begin{abstract}
The number of consumers seeking safe and health-beneficial foods is systematically increasing. Consumers demand more environmentally friendly and safe food options coming from organic farming. Blackcurrants fruits are a perfect source of biological active compounds, such as vitamin C, polyphenols and flavonoids as well anthocyanins. Organic agricultural practices have modified the level of bioactive compounds in blackcurrant fruits. The novelty and the aim of the presented study was to compare the concentrations of selected health-promoting antioxidants in fruits of three blackcurrants ('Ben Adler', 'Tiben' and 'Titania') grown in organic and conventional orchards in Poland. For bioactive compound determination, the high-performance liquid chromatography (HPLC) method was used. The obtained results showed that organic blackcurrant fruits contained significantly more vitamin C (9.4 mg/100 g f.w.), total polyphenols (189.2 mg/100 g f.w.), total phenolic acids (10.3 mg/100 g f.w.), and total flavonoids (178.8 mg/100 g f.w.), as well anthocyanins (167.9 mg/100 g f.w.), compared to conventional ones. The selected cultivars and the years of cultivation system affect the concentration of the measured polyphenols, with strong interactions between these factors. The experiment confirms the hypothesis that organic blackcurrants should be a very important part of well-balanced, healthy diet.
\end{abstract}

Keywords: black currant; polyphenols; anthocyanin; organic; conventional

\section{Introduction}

Selected plant products can be treated as a source of nutraceuticals-substances that have a health-promoting effect on the human body, including those that reduce the risk of numerous diseases [1]. In developed countries, we observe a significant increase in the incidence of diet-related diseases and diseases occurring as a result of stress on the human body, which in turn causes an increase in consumer interest in products that are naturally rich in ingredients with pro-health potential and antioxidant properties. One of the sources of such ingredients is blackcurrant fruit. Blackcurrant is a valuable and popular fruit owing to its taste and health-promoting reasons. The chemical composition and taste of currants encourage consumers to consume them both fresh and processed [2]. Ribes nigrum L. is distinguished by its high antioxidant activity, stemming from its high content of biologically active compounds, such as polyphenols, which include, among others, phenolic acids, flavonoids and anthocyanins and vitamins - mainly vitamin C [3]. Flavonols show the ability to scavenge free radicals and create chelates with metals-mainly copper-which protects vitamin $C$ from oxidation and promotes stabilization within the body. Oxidative stress is one of the early civilization diseases, where uncontrolled negative forms and free radicals affect the reduced mechanisms of cell control. The state of increased oxidative stress is observed in the course of inflammatory diseases and in smokers [4]. The flavonoid group is also attributed with positive effects on the cardiovascular system, mainly caused by quercetin and rutin. Quercetin prevents oxidation of low-density lipoproteins (LDL), thus reducing the risk of atherosclerosis [3]. The remaining flavonoid polyphenols can 
be used for prophylactic and therapeutic purposes in various civilization diseases due to their antioxidant properties [5]. In a study with hypercholesterolemia patients, purified anthocyanin extract was administered, which improved endothelial-dependent blood vessels. The improvement effect is caused by activation of NO-cGMP signaling pathway, resulting in enhancement of the serum lipid profile and inflammation. Rutin shows synergism in relation to vitamin $C$, due to its ability to strengthen blood vessel walls and promote flexibility. Apart from the abovementioned bioactive compounds, minerals such as calcium, magnesium and potassium are also responsible for their antioxidant character. It is worth mentioning that blackcurrant possesses the highest non-heme iron content of all fruits available in Poland; its bioavailability to the body is increased due to the favorable vitamin $\mathrm{C}$ ratio, which is also a richly available resource [6-8]. Moreover, it should be noted that the amount of polyphenolic compounds, including anthocyanins, and antioxidant, anti-inflammatory and health-promoting properties, are similar to the data obtained from chokeberry fruit. However, the taste of blackcurrant, compared to chokeberry, is more acceptable by potential consumers. Additionally, the price and availability of blackcurrant fruit-fresh and frozen, as well as products derived from the fruit-allows for easier application in the diet. The content of biologically active compounds and minerals in blackcurrant depends primarily on genetic factors and variety, as well as modifications caused by environmental factors, such as ambient temperature, light, humidity and cultivation method $[9,10]$.

In recent decades, there has been progress in research on the analysis of the composition and evaluation of the content of health-promoting ingredients in selected plant products, including blackcurrant fruit. It should be noted, however, that a significant part of the research conducted on extracts, pomace or preserves (juices) was obtained from the black cup and not their fruit. Additionally, these studies usually refer to the raw material obtained from conventional crops. At the same time, we observe a clear increase in organic production, projected to reach $25 \%$ of agricultural land under organic farming by 2030 [11]. The potential of the developing market, combined with the consumers' desire to improve their lifestyle, encourage comparative studies to assess the content of compounds with health-promoting potential in organic and conventional cultivation conditions. In addition, conducting observations in a cycle longer than one year allows for the elimination of numerous factors related to, inter alia, edaphoclimatic conditions.

Herein, we aimed to identify and determine the content of bioactive compounds, such as polyphenols, including anthocyanins, in three different blackcurrant varieties from organic and conventional farming. Data regarding polyphenols content in currant cultivars are available in the literature, but the knowledge about the quality of bioactive compounds in plants obtained from different cultivation systems is still insufficient. The experimental data were gathered over a two year period to ensure that the obtained results were not a random effect.

\section{Materials and Methods}

\subsection{Plant Material}

Fruits of three varieties of currant cultivars, 'Ben Adler', 'Tiben', and 'Titania', were obtained from two plantations: organic and conventional. The location of the organic farm was Podkarpackie Province, Mielec County, Czermin Municipality, Wola Otałęska $\left(50^{\circ} 21^{\prime} 24.55^{\prime \prime} \mathrm{N} ; 21^{\circ} 15^{\prime} 41.58^{\prime \prime} \mathrm{E}\right)$. The location of the conventional farm was Podkarpackie Province, Mielec County, Czermin Municipality, Ziempniów (50¹9'8.01" N; 21 ${ }^{\circ} 13^{\prime} 59.64^{\prime \prime}$ E). The distance between plantations was about $6 \mathrm{~km}$. From each variety and farm, 4 samples of $1 \mathrm{~kg}$ of fruit were taken from different plantation sites. The number of repetitions were $n=8$ for variety and $n=4$ for system. We maintained an identical arrangement in two years of experience (2014 and 2015). In the organic farm, fermented cattle manure $(0.6 \% \mathrm{~N}, 0.7 \%$ $\mathrm{P}, 0.3 \% \mathrm{Mg}, 0.7 \% \mathrm{~K}, 0.7 \% \mathrm{Ca}$, one year before planting the bushes on the plantation) in the amount of $20 \mathrm{t} /$ ha was used for fertilization. In the conventional farm, mineral fertilizers Azophoska (13.6\% total nitrogen, 5.5\% $\mathrm{N}-\mathrm{NO}_{3}$ and 8.1\% $\mathrm{N}-\mathrm{NH}_{3}, 6.4 \% \mathrm{P}_{2} \mathrm{O}_{5}, 19.1 \% \mathrm{~K}_{2} \mathrm{O}$, 
$4.5 \% \mathrm{MgO})$ and polymag $\mathrm{S}\left(10.0 \% \mathrm{~N}-\mathrm{NH}_{3}, 8.0 \% \mathrm{P}_{2} \mathrm{O}_{5}, 15.0 \% \mathrm{~K}_{2} \mathrm{O}, 4.5 \% \mathrm{MgO}, 35.0 \%, \mathrm{SO}_{3}\right.$, $0.1 \% \mathrm{~B}, 0.2 \% \mathrm{Mn}$ ) were used. Mineral fertilizers were applied in the amount of $420 \mathrm{~kg} / \mathrm{ha}$ and $180 \mathrm{~kg} / \mathrm{ha}$, respectively. In the organic farm, no protection against diseases and pests was applied. In the conventional farm, protection against currant leaf cover and input-rash rust was applied, using Dithane M-45 80 WP. Additionally, twice Mospilan 20 SP was used to protect against currant pimples. Detailed information about weather conditions (minimum and maximum temperatures, number of hours of sunshine per day and rainfall) in the experimental farms are presented in Table 1. Due to the location of both farms in the same geographical region and observation over the period of 2 years, it was noticed that the temperature, rainfall and sunlight conditions during the growing season of currants during the study were similar forboth experimental farms. The scheme of the study design is presented in Figure 1.

Table 1. Weather conditions in experimental farms (organic and conventional) 2014-2015 in time of blackcurrant fruits development.

\begin{tabular}{|c|c|c|c|c|c|c|c|c|c|c|c|c|c|c|}
\hline \multirow{3}{*}{$\begin{array}{c}\text { Cultivation Year } \\
\text { Month }\end{array}$} & \multicolumn{8}{|c|}{ Agronomic System-Organic } & \multicolumn{6}{|c|}{ Agronomic System-Conventional } \\
\hline & \multicolumn{14}{|c|}{2014} \\
\hline & IV & $\mathbf{V}$ & VI & VII & VIII & IX & $x$ & IV & $\mathbf{V}$ & VI & VII & VIII & IX & $X$ \\
\hline maximum temperature $\left({ }^{\circ} \mathrm{C}\right)$ & 23 & 28 & 32 & 32 & 34 & 28 & 25 & 23 & 29 & 32 & 32 & 33 & 28 & 25 \\
\hline minimum temperature $\left({ }^{\circ} \mathrm{C}\right)$ & 0 & -2 & 6 & 9 & 6 & 4 & -2 & 0 & -2 & 6 & 8 & 4 & 5 & -2 \\
\hline average temperature $\left({ }^{\circ} \mathrm{C}\right)$ & 12.1 & 14.9 & 16.5 & 20.4 & 19.1 & 16.7 & 12.3 & 11.8 & 14.5 & 16.8 & 20.1 & 18.6 & 15.5 & 11.0 \\
\hline rainfall (mm/month) & 1.08 & 3.05 & 1.73 & 3.65 & 2.98 & 0.52 & 2.05 & 1.62 & 3.69 & 1.60 & 3.47 & 3.23 & 0.45 & 1.97 \\
\hline sunshine (h/day) & 6 & 7 & 8 & 7 & 8 & 6 & 5 & 6 & 9 & 7 & 8 & 7 & 6 & 5 \\
\hline Cultivation Year & \multicolumn{14}{|c|}{2015} \\
\hline Month & IV & $\mathbf{V}$ & VI & VII & VIII & IX & $x$ & IV & V & VI & VII & VIII & IX & $x$ \\
\hline maximum temperature $\left({ }^{\circ} \mathrm{C}\right)$ & 25 & 29 & 33 & 41 & 38 & 38 & 25 & 25 & 28 & 32 & 35 & 36 & 39 & 25 \\
\hline minimum temperature $\left({ }^{\circ} \mathrm{C}\right)$ & -2 & -2 & 5 & 6 & 6 & 5 & -3 & -2 & 1 & 5 & 5 & 6 & 5 & -2 \\
\hline average temperature $\left({ }^{\circ} \mathrm{C}\right)$ & 9.5 & 13.7 & 17.7 & 21.0 & 22.2 & 17.6 & 9.9 & 9.5 & 13.8 & 17.5 & 20.4 & 21.9 & 17.9 & 9.5 \\
\hline rainfall $(\mathrm{mm} / \mathrm{month})$ & 0.73 & 3.28 & 0.64 & 2.46 & 0.12 & 2.64 & 1.54 & 0.80 & 3.20 & 0.73 & 2.37 & 0.13 & 2.62 & 1.36 \\
\hline sunshine (h/day) & 6 & 8 & 8 & 8 & 8 & 6 & 4 & 6 & 8 & 9 & 7 & 8 & 6 & 5 \\
\hline
\end{tabular}

\subsection{Analytical Material Preparation}

\subsubsection{Preparation of Test Material—Lyophilization}

The fruits were delivered to the laboratory in polystyrene containers with cooling inserts. Next, the fruits were separated from the stalks. Half of each batch of fruit was used to measure dry matter and the other half was used to lyophilize.

\subsubsection{Freeze-Drying}

Fruits from individual combinations were mixed into a uniform pulp and freezedried with the Labconco (Warsaw, Poland, $-40{ }^{\circ} \mathrm{C}$, pressure $0.100 \mathrm{mBar}$ ) 2.5 freeze-dryer ( $96 \mathrm{~h}, 0.100 \mathrm{mbar},-50^{\circ} \mathrm{C}$ ). After freeze-drying, the samples were ground in the mill A-11 $\left(\mathrm{IKA}^{\circledR}\right.$-Werke GmbH \& Co. KG, Staufen im Breisgau, Germany) laboratory mill and kept in scintillation vessels at $-80^{\circ} \mathrm{C}$.

\subsection{Chemical Analyses}

\subsubsection{Dry Matter Analysis}

The content of dry matter in the fruits was measured by weight method PN-R04013:1988 [12]. A glass vessel was weighed, then a certain amount of currant pulp was applied to the vessel. The vessel was weighed again and placed in a FP-25W Farma Play (Tczew, Poland) dryer. The drying time was $96 \mathrm{~h}$ at a temperature of $105^{\circ} \mathrm{C}$. After the specified time, the pot was placed into a desiccator and cooled to room temperature $\left(21^{\circ} \mathrm{C}\right)$ 
and then weighed. From the difference of masses before and after drying, the dry matter content in the examined currant cultivar was calculated.

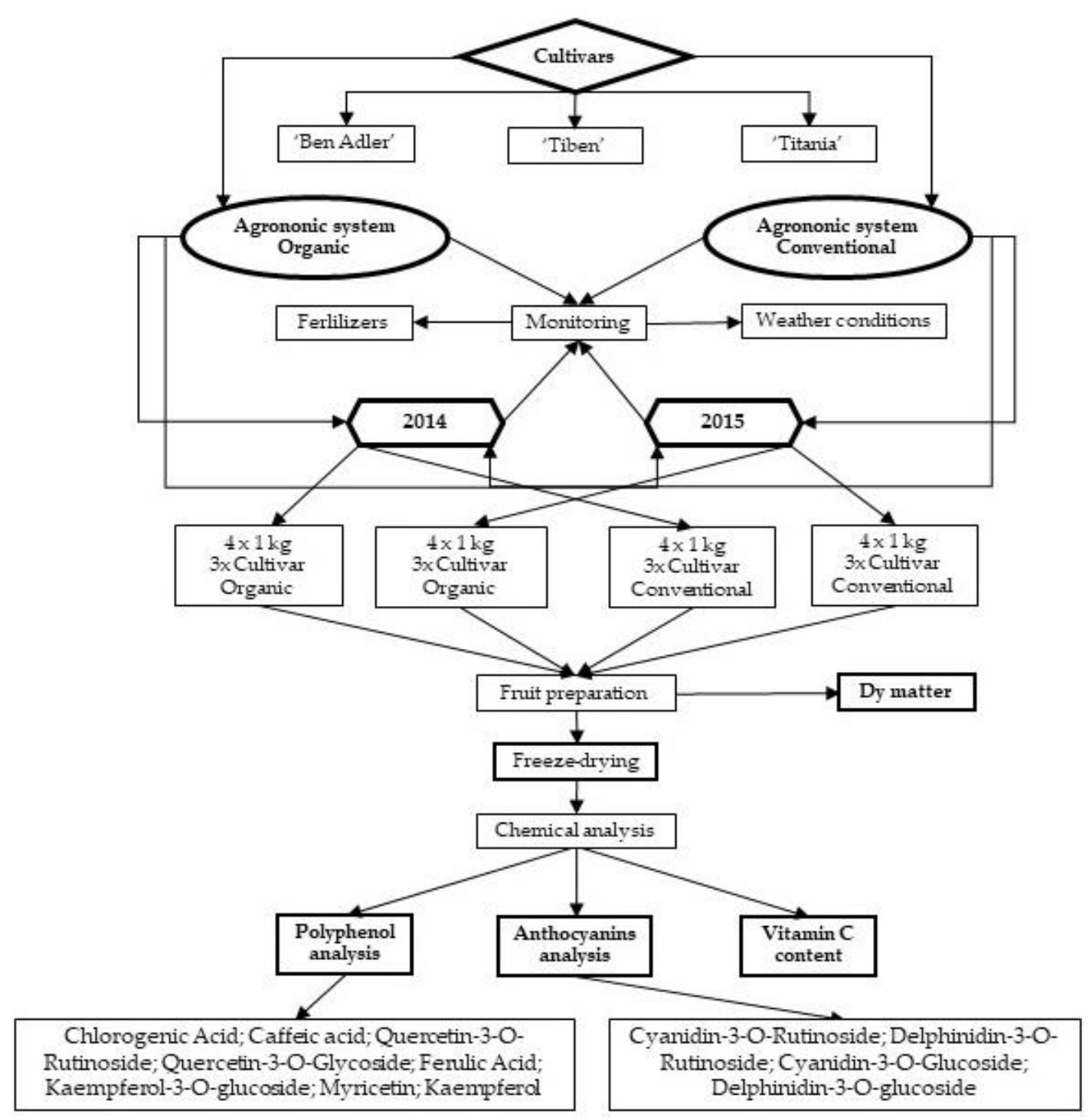

Figure 1. Graphical scheme of study design.

\subsubsection{Polyphenols Analysis}

Polyphenols were performed by the HPLC method [13]. A total of $100 \mathrm{mg}$ of freezedried blackcurrant powder was mixed with $5 \mathrm{~mL}$ of $80 \%$ methanol (HPLC-grade). Next, the sample was shaken on a Vortex $326 \mathrm{M}$ (Marki, Poland). All samples were extracted in an ultrasonic bath $\left(10 \mathrm{~min}, 30^{\circ} \mathrm{C}, 5500 \mathrm{~Hz}\right)$. After $10 \mathrm{~min}$ of extraction, the fruit samples were transferred to a centrifuge ( $10 \mathrm{~min}, 3789 \times \mathrm{g}, 5^{\circ} \mathrm{C}$ ). A total of $900 \mu \mathrm{L}$ of supernatant was injected into HPLC vials and analyzed, with an injection volume of $100 \mu$ l. For polyphenol compound separation and identification, Synergi Fusion-RP 80i column $250 \times 4.60 \mathrm{~mm}$ (Phenomenex, Warsaw, Poland) was used. Analysis was carried out using Shimadzu equipment (West Chicago, IL, U.S.A.): two LC-20AD pumps, a CBM-20A controller, a SIL-20AC column oven, and a UV/Vis SPD-20 AV spectrometer. The phenolic compounds were separated under gradient conditions at a flow rate of $1 \mathrm{~mL} / \mathrm{min}$. Two gradient phases were used: $10 \%$ acetonitrile and ultra-pure water (phase A), and 55\% (v:v) acetonitrile and ultrapure water (phase B). The phases were acidified with ortho-phosphoric acid ( $\mathrm{pH}$ 3.0). The total time of the analysis was $38 \mathrm{~min}$. The phase-time program was as 
follows: $1.00-22.99 \mathrm{~min}, 95 \%$ phase $\mathrm{A}$ and $5 \%$ phase $\mathrm{B} ; 23.00-27.99 \mathrm{~min}, 50 \%$ phase A and $50 \%$ phase B; 28.00-28.99 $\mathrm{min}, 80 \%$ phase A and $20 \%$ phase B; and $29.00-38.00 \mathrm{~min}$, $95 \%$ phase $A$ and $5 \%$ phase $B$. The wavelengths of detection were $250 \mathrm{~nm}$ for phenolic acids and $370 \mathrm{~nm}$ for flavonols. The phenolic compounds were identified using $99.9 \%$ pure standards (Sigma-Aldrich, Warsaw, Poland) and the retention times of the standards. HPLC chromatograms presenting the time of retention and profiles of the identified phenolic acids and flavonols are presented in Figures 2 and 3, respectively. The concentration of the compounds was calculated based on standard curves and applied dilution coefficients (Figure S2a, added in Supplementary Materials).
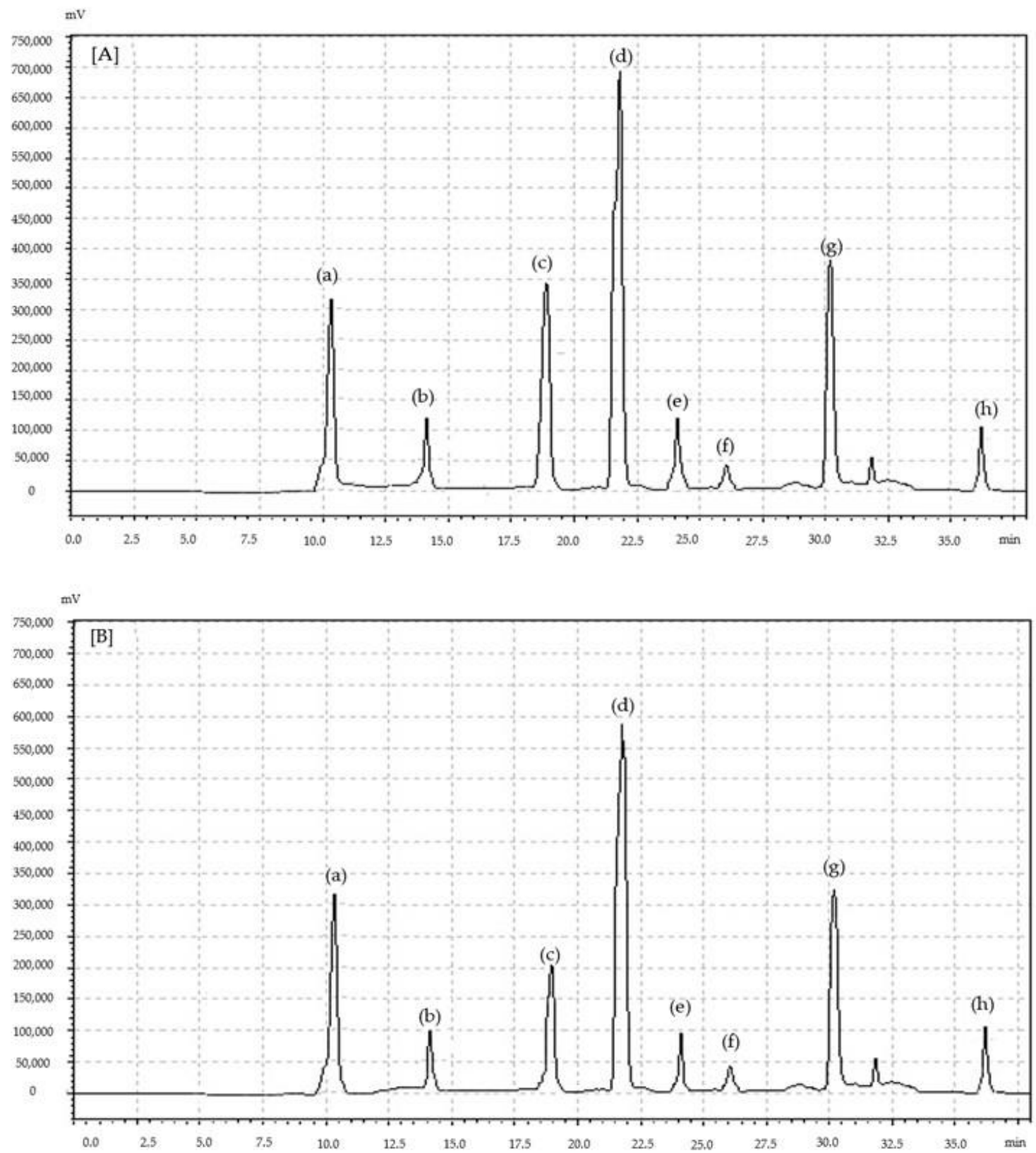

Figure 2. Chromatograms showing retention times for polyphenols (phenolic acids and flavonoids) in organic (A) and conventional (B) blackcurrant; (a) chlorogenic, (b) caffeic, (c) quercetin-3-O-rutinoside, (d) ferulic acid, (e) kaempferol-3-Oglucoside, (f) myricetin, (g) quercetin-3-O-glucoside, (h) kaempferol. 

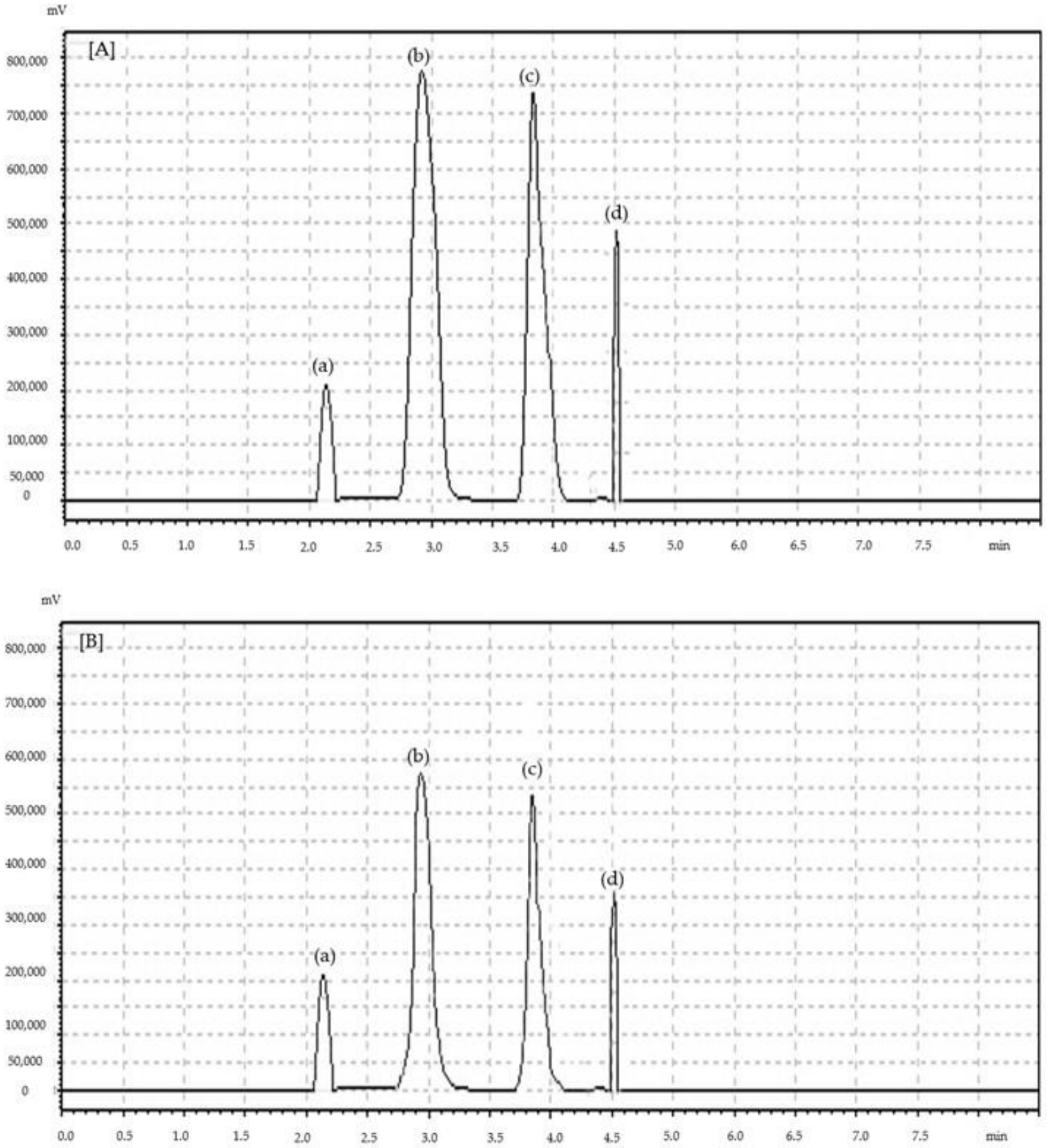

Figure 3. Chromatograms showing retention times anthocyanins in organic (A) and conventional (B) blackcurrant; (a) cyanidin-3-O-rutinoside, (b) delphinidin-3-O-rutinoside, (c) delphinidin-3-O-glucoside, (d) cyanidin-3-O-glucoside.

\subsubsection{Anthocyanins Analysis}

The first stage of sample preparation for analysis of anthocyanin compounds was combined with the analysis of the polyphenols. Then, after the sample was swirled, $2.5 \mathrm{~mL}$ was taken, and $2.5 \mathrm{~mL} \mathrm{HCL}$ (pure grade) and $5 \mathrm{~mL}$ methanol (HPLC-grade) were added. The samples were mixed and placed in a refrigerator $\left(5^{\circ} \mathrm{C}, 10 \mathrm{~min}\right)$. The samples were then subjected to HPLC-grade analysis. The HPLC set comprised the following: two pumps LC-20AD, controller CBM-20A, column oven SIL-20AC, and spectrometer UV/Vis SPD-20 AV. The injection volume was $100 \mu \mathrm{l}$ in the analytical column: Phenomenex Fusion 80-A (C-18) $4.6 \times 250 \mathrm{~mm}$, particle size $4 \mu \mathrm{m}$. The anthocyanins were separated under isocratic conditions with a flow rate of $1.5 \mathrm{~mL} \mathrm{~min}-1$. For one mobile phase, $5 \%$ 
acetic acid, acetonitrile, and methanol (70:10:20) were used. The wavelength range for detection was $530 \mathrm{~nm}$. Anthocyanins were identified based on 99.9\% pure standards (SigmaAldrich, Poznań, Poland), external standards (cyanidin-3-O-rutinoside, delphinidin-3-Orutinoside, cyanidin-3-O-glucoside, del-phinidin-3-O-glucoside), and the analysis times for the standards. The concentration of the compounds was calculated based on standard curves and applied dilution coefficients (Figure S3b, added in Supplementary Materials).

\subsubsection{Vitamin C Content}

A total of $100 \mathrm{mg}$ of powdered, freeze-dried blackcurrant powder was weighed in a plastic tube. Then, $5 \mathrm{~mL}$ of $5 \%$ meta-phosphoric acid was added. Samples were mixed in vortex and extracted in an ultrasonic bath under the following conditions: $10 \mathrm{~min}$ at $20^{\circ} \mathrm{C}, 5500 \mathrm{~Hz}$ (PolSonic Warsaw, Poland,). Next, all samples were centrifuged under the following conditions: $10 \mathrm{~min}, 3780 \times \mathrm{g}, 0^{\circ} \mathrm{C}$ (Centrifuge Hermle Z 300 k Mirków, Poland). The supernatant was gently transferred into orange HPLC-vial and $100 \mu \mathrm{L}$ was used for analysis injection. The following analysis parameters were used: mobile phase acetic buffer $\mathrm{pH}$ 4.4. The equipment used for vitamin $\mathrm{C}$ analysis was a Shimadzu HPLC-set (sales representative: Shimazu, Warsaw, Poland, manufacturing Shimazu Inc., Tampa, FL, U.S.A.: two pumps LC-20AD, controller CBM-20A, column oven SIL-20AC, spectrometer UV-vis: SPD-20AV), and a Phenomenex Hydro 80-A RP column $(250 \times 4.6 \mathrm{~mm})$ (Phenomenex, Shimpol, Warsaw, Poland) with an analysis time of $18 \mathrm{~min}$ and a detection wavelength of $260 \mathrm{~nm}$. L-ASC and DHA standards were obtained from Fluka and Sigma-Aldrich (Warsaw, Poland) with $99 \%$ purity. For each experimental combination, four replicates were obtained. Five injections of L-ASC and DHA standards were generated from the prepared standard solutions, and standard curves of tested components of vitamin $C$ were determined. The chromatogram was analyzed, and individual compounds were identified based on the retention time of the standards [14].

\subsection{Statistical Analysis}

The obtained results were statistically analyzed. The 3-factor analysis of variance (ANOVA) was performed using a linear-mixed effects model, with year, currant cultivar and production system. In addition, for further explanation of the identified interactions, two-factor ANOVA, with production system and cultivar as factors, followed by post hoc Tukey's honesty significant difference (HDS) test $(\alpha=0.005)$, were performed separately from each of the two vegetation seasons. The number of samples per system of production was $n=24$, and the number of samples per product was $n=12$. A lack of a statistically significant difference $(p>0.05)$ is described in Tables $2-4$ as N.S. Different letters within a row indicate statistically significant differences at the level $p<0.05$. PCA (Principal Component Analysis) was performed with Statistica 13.0 software (Tibco Software Inc., Palo Alto, CA, USA). 


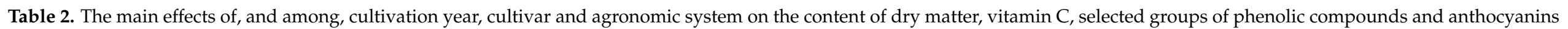
in blackcurrant fruits (in mg $100 \mathrm{~g}$ f.w.).

\begin{tabular}{|c|c|c|c|c|c|c|c|c|c|}
\hline $\begin{array}{l}\text { Production } \\
\text { System }\end{array}$ & Dry Matter ${ }^{1}$ & DHA $^{2}$ & L-ASC $^{2}$ & Vitamin $C^{1}$ & $\begin{array}{l}\text { Polyphenols } \\
\text { (Sum) }^{1}\end{array}$ & $\begin{array}{l}\text { Phenolic Acids } \\
\text { (Sum) }{ }^{1}\end{array}$ & Flavonoids (Sum) ${ }^{1}$ & $\begin{array}{l}\text { Flavonols } \\
\text { (Sum) }^{1}\end{array}$ & $\begin{array}{l}\text { Anthocyanin } \\
\text { (Sum) }^{1}\end{array}$ \\
\hline \multicolumn{10}{|c|}{ Cultivation Year (CY) } \\
\hline 2014 & $20.62 \pm 0.60 \mathrm{a}^{3}$ & $9.82 \pm 0.28$ a & $137.62 \pm 4.59 \mathrm{a}$ & $147.43 \pm 4.79 \mathrm{a}$ & $183.07 \pm 6.034 b$ & $10.45 \pm 0.26 \mathrm{a}$ & $172.62 \pm 5.81 \mathrm{~b}$ & $9.94 \pm 0.54 \mathrm{a}$ & $162.67 \pm 5.38 b$ \\
\hline 2015 & $19.76 \pm 0.53 b$ & $9.11 \pm 0.29 \mathrm{~b}$ & $125.95 \pm 3.89 \mathrm{~b}$ & $135.05 \pm 4.09 \mathrm{~b}$ & $190.53 \pm 6.40 \mathrm{a}$ & $10.50 \pm 0.28 \mathrm{a}$ & $180.03 \pm 6.16 \mathrm{a}$ & $9.67 \pm 0.54 \mathrm{~b}$ & $170.36 \pm 5.77 \mathrm{a}$ \\
\hline \multicolumn{10}{|c|}{ Cultivar (CL) } \\
\hline Ben Adler & $20.72 \pm 0.33 \mathrm{a}$ & $9.16 \pm 0.17 \mathrm{c}$ & $146.73 \pm 3.02 \mathrm{a}$ & $155.89 \pm 3.19 \mathrm{a}$ & $195.84 \pm 4.76 \mathrm{~b}$ & $10.65 \pm 0.98 b$ & $185.19 \pm 4.71 \mathrm{c}$ & $10.78 \pm 0.41 \mathrm{a}$ & $174.41 \pm 4.32 \mathrm{~b}$ \\
\hline Tiben & $19.52 \pm 1.18 \mathrm{c}$ & $9.26 \pm 0.55 \mathrm{~b}$ & $113.13 \pm 5.79 \mathrm{a}$ & $122.38 \pm 6.34 \mathrm{c}$ & $166.10 \pm 9.25 c$ & $10.12 \pm 0.48 \mathrm{a}$ & $155.98 \pm 8.78 \mathrm{~b}$ & $9.85 \pm 0.88 \mathrm{~b}$ & $146.13 \pm 7.91 \mathrm{c}$ \\
\hline Titania & $20.34 \pm 0.30 \mathrm{~b}$ & $9.97 \pm 0.19 \mathrm{a}$ & $135.19 \pm 2.87 \mathrm{~b}$ & $145.46 \pm 3.05 b$ & $198.45 \pm 5.39 \mathrm{a}$ & $10.65 \pm 0.29 \mathrm{a}$ & $187.80 \pm 5.16 \mathrm{a}$ & $8.80 \pm 2.11 \mathrm{c}$ & $179.00 \pm 18.92 \mathrm{a}$ \\
\hline \multicolumn{10}{|c|}{ Agronomic System (AS) } \\
\hline $\begin{array}{c}\text { organic } \\
\text { conventional }\end{array}$ & $\begin{array}{l}22.06 \pm 0.33 a \\
18.32 \pm 0.49 b\end{array}$ & $\begin{array}{l}9.44 \pm 0.18 \mathrm{a} \\
8.46 \pm 0.22 \mathrm{~b}\end{array}$ & $\begin{array}{l}129.42 \pm 2.33 \mathrm{a} \\
120.21 \pm 4.69 \mathrm{~b}\end{array}$ & $\begin{array}{l}138.85 \pm 2.31 \mathrm{a} \\
128.68 \pm 4.89 \mathrm{~b}\end{array}$ & $\begin{array}{l}189.15 \pm 2.71 \mathrm{a} \\
163.75 \pm 4.99 \mathrm{~b}\end{array}$ & $\begin{array}{c}10.33 \pm 0.12 \mathrm{a} \\
9.50 \pm 0.22 \mathrm{~b}\end{array}$ & $\begin{array}{l}178.84 \pm 2.70 \mathrm{a} \\
154.25 \pm 4.81 \mathrm{~b}\end{array}$ & $\begin{array}{l}10.89 \pm 0.24 \mathrm{a} \\
7.53 \pm 0.53 \mathrm{~b}\end{array}$ & $\begin{array}{l}167.96 \pm 2.72 \mathrm{a} \\
146.72 \pm 4.73 \mathrm{~b}\end{array}$ \\
\hline \multicolumn{10}{|c|}{ ANOVA $p$-Values } \\
\hline $\mathrm{CY}$ & $<0.001$ & $<0.001$ & NS & $<0.001$ & NS & NS & NS & NS & NS \\
\hline $\mathrm{CL}$ & $\mathrm{NS}^{4}$ & $<0.001$ & $<0.001$ & $<0.001$ & NS & $<0.001$ & $<0.001$ & $<0.001$ & $<0.001$ \\
\hline AS & NS & $<0.001$ & NS & NS & $<0.001$ & $<0.001$ & $<0.001$ & $<0.001$ & $<0.001$ \\
\hline $\mathrm{CY} \times \mathrm{AS}$ & NS & $<0.001$ & NS & NS & $<0.001$ & $<0.001$ & $<0.001$ & $<0.001$ & $<0.001$ \\
\hline $\mathrm{CL} \times \mathrm{AS}$ & 0.003 & $<0.001$ & $<0.001$ & $<0.001$ & $<0.001$ & $<0.001$ & $<0.001$ & $<0.001$ & $<0.001$ \\
\hline $\mathrm{CY} \times \mathrm{CL} \times \mathrm{AS}$ & NS & $<0.001$ & NS & $<0.001$ & NS & 0.002 & $<0.001$ & 0.002 & NS \\
\hline
\end{tabular}

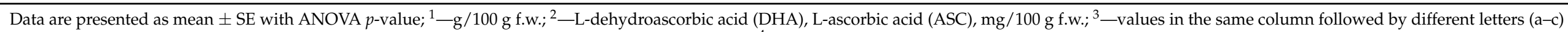
are significantly different at $5 \%$ level of probability, with "a" always representing the highest value; ${ }^{4}$-not significant (NS). 


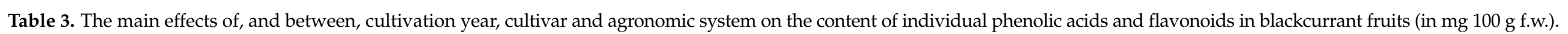

\begin{tabular}{|c|c|c|c|c|c|c|c|c|}
\hline Production System & Chlorogenic Acid ${ }^{1}$ & Caffeic Acid ${ }^{1}$ & Quercetin-3-O-Rutinoside ${ }^{1}$ & Quercetin-3-O-Glycoside $^{1}$ & Ferulic Acid ${ }^{1}$ & Kaempferol-3-O-Glucoside $^{1}$ & Myricetin $^{1}$ & Kaempferol $^{1}$ \\
\hline \multicolumn{9}{|c|}{ Cultivation Year (CY) } \\
\hline 2014 & $4.66 \pm 0.22 \mathrm{a}^{2}$ & $1.08 \pm 0.07 \mathrm{a}$ & $4.22 \pm 0.26 \mathrm{a}$ & $2.79 \pm 0.23 \mathrm{a}$ & $4.71 \pm 0.11 \mathrm{~b}$ & $1.80 \pm 0.19 \mathrm{a}$ & $0.77 \pm 0.02 \mathrm{a}$ & $0.36 \pm 0.01 \mathrm{a}$ \\
\hline 2015 & $4.36 \pm 0.21 \mathrm{~b}$ & $1.05 \pm 0.07 \mathrm{a}$ & $3.89 \pm 0.29 b$ & $2.85 \pm 0.21 \mathrm{a}$ & $5.08 \pm 0.13 a$ & $1.83 \pm 0.13 \mathrm{a}$ & $0.75 \pm 0.02 \mathrm{~b}$ & $0.35 \pm 0.01 \mathrm{~b}$ \\
\hline \multicolumn{9}{|c|}{ Cultivar (CL) } \\
\hline Ben Adler & $5.25 \pm 0.15 \mathrm{a}$ & $0.70 \pm 0.04 \mathrm{a}$ & $4.16 \pm 0.17 \mathrm{~b}$ & $3.35 \pm 0.15 \mathrm{a}$ & $4.70 \pm 0.16 \mathrm{~b}$ & $2.12 \pm 0.10 \mathrm{a}$ & $0.80 \pm 0.01 \mathrm{a}$ & $0.35 \pm 0.01 \mathrm{~b}$ \\
\hline Tiben & $4.43 \pm 0.33 \mathrm{~b}$ & $1.05 \pm 0.04 \mathrm{~b}$ & $4.82 \pm 0.39 \mathrm{a}$ & $1.89 \pm 0.26 \mathrm{~b}$ & $4.73 \pm 0.13 b$ & $2.07 \pm 0.19 \mathrm{~b}$ & $0.71 \pm 0.04 \mathrm{~b}$ & $0.35 \pm 0.02 \mathrm{~b}$ \\
\hline Titania & $3.95 \pm 0.15 c$ & $1.45 \pm 0.04 \mathrm{c}$ & $3.18 \pm 0.30 \mathrm{~b}$ & $3.22 \pm 0.21 \mathrm{a}$ & $5.25 \pm 0.14 \mathrm{a}$ & $1.26 \pm 0.02 \mathrm{c}$ & $0.77 \pm 0.22 \mathrm{ab}$ & $0.36 \pm 0.01 \mathrm{a}$ \\
\hline organic & $4.89 \pm 0.12 \mathrm{a}$ & $1.18 \pm 0.06 \mathrm{a}$ & $5.06 \pm 0.21 \mathrm{a}$ & $3.60 \pm 0.12 \mathrm{a}$ & $5.38 \pm 0.08 \mathrm{a}$ & $2.19 \pm 0.14 \mathrm{a}$ & $0.83 \pm 0.01 \mathrm{a}$ & $0.39 \pm 0.01 \mathrm{a}$ \\
\hline conventional & $4.19 \pm 0.26 \mathrm{~b}$ & $0.95 \pm 0.07 \mathrm{~b}$ & $3.04 \pm 0.16 \mathrm{~b}$ & $2.04 \pm 0.18 \mathrm{~b}$ & $4.41 \pm 0.07 \mathrm{~b}$ & $1.45 \pm 0.04 \mathrm{~b}$ & $0.69 \pm 0.02 b$ & $0.32 \pm 0.01 \mathrm{~b}$ \\
\hline \multicolumn{9}{|c|}{ ANOVA $p$-Values } \\
\hline $\mathrm{CY}$ & $\mathrm{NS}^{3}$ & NS & NS & NS & NS & NS & NS & NS \\
\hline $\mathrm{CL}$ & $<0.001$ & NS & $<0.001$ & $<0.001$ & NS & $<0.001$ & $<0.001$ & $<0.001$ \\
\hline AS & $<0.001$ & NS & 0.022 & 0.015 & NS & $<0.001$ & $<0.001$ & NS \\
\hline $\mathrm{CY} \times \mathrm{CL}$ & $<0.001$ & $<0.001$ & $<0.001$ & $<0.001$ & $<0.001$ & $<0.001$ & $<0.001$ & $<0.001$ \\
\hline $\mathrm{CY} \times \mathrm{AS}$ & $<0.001$ & NS & NS & NS & $<0.001$ & $<0.001$ & $<0.001$ & NS \\
\hline $\mathrm{CY} \times \mathrm{CL} \times \mathrm{AS}$ & $<0.001$ & $<0.001$ & 0.090 & $<0.001$ & 0.002 & $<0.001$ & $<0.001$ & $<0.001$ \\
\hline
\end{tabular}

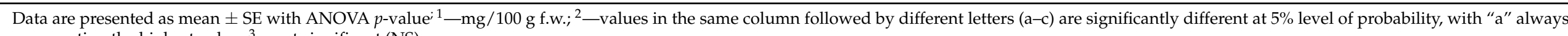

representing the highest value; ${ }^{3}$ - not significant (NS). 
Table 4. The main effects of, and between, cultivation year, cultivar and agronomic system on the content of individual anthocyanins in blackcurrant fruits (in mg $100 \mathrm{~g}$ f.w.).

\begin{tabular}{|c|c|c|c|c|}
\hline Production System & Cyanidin-3-O-Rutinoside $^{1}$ & Delphinidin-3-O-Rutinoside $^{1}$ & Cyanidin-3-O-Glucoside $^{1}$ & Delphinidin-3-O-Glucoside $^{1}$ \\
\hline \multicolumn{5}{|c|}{ Cultivation Year (CY) } \\
\hline 2014 & $19.57 \pm 0.56 \mathrm{a}^{2}$ & $91.93 \pm 3.92 b$ & $8.01 \pm 0.24 \mathrm{a}$ & $43.17 \pm 0.93 \mathrm{a}$ \\
\hline \multicolumn{5}{|c|}{ Cultivar (CL) } \\
\hline Ben Adler & $19.90 \pm 0.34 \mathrm{a}$ & $101.38 \pm 2.95 b$ & $7.98 \pm 0.15 b$ & $42.66 \pm 1.39 \mathrm{a}$ \\
\hline Tiben & $18.51 \pm 1.02 \mathrm{~b}$ & $78.64 \pm 5.10 \mathrm{c}$ & $7.29 \pm 0.42 c$ & $38.70 \pm 1.73 c$ \\
\hline \multicolumn{5}{|c|}{ Agronomic System (AS) } \\
\hline organic & $20.78 \pm 0.33 \mathrm{a}$ & $109.93 \pm 2.63 \mathrm{a}$ & $8.52 \pm 0.11 \mathrm{a}$ & $44.33 \pm 0.71 \mathrm{a}$ \\
\hline conventional & $17.26 \pm 0.44 \mathrm{~b}$ & $81.91 \pm 3.46 \mathrm{~b}$ & $7.07 \pm 0.22 \mathrm{~b}$ & $37.23 \pm 0.91 \mathrm{~b}$ \\
\hline \multicolumn{5}{|c|}{ ANOVA $p$-values } \\
\hline CY & $\mathrm{NS}^{3}$ & NS & NS & NS \\
\hline $\mathrm{CL}$ & $<0.001$ & $<0.001$ & $<0.001$ & $<0.001$ \\
\hline AS & 0.010 & 0.023 & $<0.001$ & NS \\
\hline $\mathrm{CY} \times \mathrm{AS}$ & 0.029 & $<0.001$ & $<0.001$ & 0.002 \\
\hline $\mathrm{CL} \times \mathrm{AS}$ & $<0.001$ & $<0.001$ & $<0.001$ & $<0.001$ \\
\hline $\mathrm{CY} \times \mathrm{CL} \times \mathrm{AS}$ & 0.002 & 0.018 & $<0.001$ & $<0.001$ \\
\hline
\end{tabular}

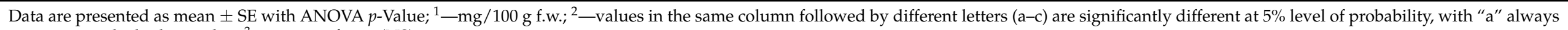
representing the highest value; ${ }^{3}$-not significant (NS). 


\section{Results and Discussion}

\subsection{Dry Matter}

The topic of comparing the content of biologically active compounds in different varieties of blackcurrant, taking into account the system of cultivation (organic vs. conventional) is constantly being studied.

Blackcurrant fruits, due to their short-term availability as a fresh product, are mainly used for processing. Hence, special attention is paid to the quality of the currant berries that enter industry, including dry matter and vitamin $C$ content. The average dry matter content (Table 2) in blackcurrant fruits from organic farming (22.06 g/100 g f.w.) and conventional system (18.32 g/100 g f.w.) display significant differences, where a similar lack of differentiation is shown depending on the currant cultivar. Variations in dry matter content are observed for the cultivation years 2014 (20.62 g/100 g f.w.) and 2015 (19.76 g/100 g f.w.) in which markable differences are found in the case of cultivar vs. agronomic system. Our study shows that no outflow of individual cultivars and cultivation systems on dry matter content is found. However, dry matter content is slightly higher for organic blackcurrants (18.58 g/100 g f.w.), compared to conventional ones (18.08 g/100 g f.w.). The results were obtained in the study by Mattila et al. [10] in which 32 ('Stella 2', 'Hietala', 'Osmolan Musta', 'Koskisen Musta', 'Brödtorp Nr.'2, 'Ri163', 'Ri409', 'Råkobb', 'Gerby', 'Nikkala', 'Osmola', 'Peräpohjolan Musta', 'Kristin', 'Janslunda', 'Suvi 7', 'Polar', 'Öjebyn', 'Boskoop Giant', 'Månstorp', 'Ri225', 'Suontaan Iso Musta', 'Brödtorp', 'Poesia', 'Ri159', 'Karila', 'Mortti', 'Marski', 'Haakon', 'Ri318', 'Melalahti', 'Mikael', 'Ri550') conventional currant cultivars were analyzed. The average dry matter content for fruits is $19.7 \mathrm{~g} / 100 \mathrm{~g}$ f.w. Furthermore, Sasnauskas et al. [15] reported similar dry matter content during the evaluation of blackcurrant varieties ('Binar', 'Gagatai', 'Intercontinental', 'Jadrenaja', 'Polar', 'Poezija', 'Storklas', 'Veloj') cultivated in Lithuania in the conventional system, where the average dry weight was $24.25 \mathrm{~g} / 100 \mathrm{~g}$ f.w.

\subsection{Phenolic Compound}

Blackcurrant fruits contain phenolic compounds, such as phenolic acids, flavonols, flavan-3-ols (catechins) and tannins, with potential health-promoting properties, making them a functional food ingredient. According to the obtained results, the average content of total polyphenols is significantly higher for organic currants $(189.15 \mathrm{mg} / 100 \mathrm{~g}$ f.w.) than for conventional ones ( $128.68 \mathrm{mg} / 100 \mathrm{~g}$ f.w.). Differentiation of total polyphenols content is also shown for individual cultivars of which the highest polyphenols content is observed for the 'Titania' cultivar (198.45 mg/100 g f.w.) and the lowest for the 'Tiben' cultivar (166.10 mg/100 g f.w.). Similar results were obtained by Wojdyło et al. in [16], in which they analyzed three varieties of blackcurrant ('Ben Hope', 'Ben Alder', 'Titania'), both from organic and conventional cultivation. They found that the average content of polyphenols for fruits from organic cultivation was $183.1 \mathrm{mg} / 100 \mathrm{~g} \mathrm{~d} . \mathrm{m}$., which is higher compared to conventional ones $154.3 \mathrm{mg} / 100 \mathrm{~g} \mathrm{~d} . \mathrm{m}$. Moreover, a significant influence of the cultivation method on the polyphenol content was determined. Similar to our own study, the highest polyphenol content was found in organic 'Ben Alder' variety (225.3 mg/100 g d.m.). As shown by Mattila et al. [10], the flavonoid content for blackcurrant varieties ranged between $9.6 \mathrm{mg} / 100 \mathrm{~g}$ f.w. and $21.6 \mathrm{mg} / 100 \mathrm{~g}$ f.w., while the average content of these compounds was $14.32 \mathrm{mg} / 100 \mathrm{~g}$ f.w. As shown in Table 2, the content of phenolic acids, flavonoids and flavonols is significantly different both for individual varieties and cultivation methods. Relationships are also observed (Table $2, p<0.001$ ) for the magnitude of variance for the year of cultivation vs. cultivar, the year of cultivation vs. cultivation methods, and for phenolic acids, flavonoids and flavonoids as well as for the year and method of cultivation and cultivar. Detailed analysis (Table 3) of individual phenolic acids and flavonoids indicates variations in the content of chlorogenic acid, kaempferol-3-O-glucoside and myricetin for individual varieties and cultivation systems, but do not show a relationship related to year of cultivation. This is confirmed via analysis of variance, indicating the relationship between the year vs. currant variety, year vs. cultivation system and variety 
vs. cultivation system. Quercetin-3-O-rutinoside and quercetin-3-O-glycoside show a relationship between the varieties and cultivation system, which is not found for caffeic acid, ferulic acid and kaempferol. All analyzed phenolic acids, flavanols and flavonoids show a distinct relationship between variants for the year of cultivation vs. cultivation system and variety. Similar results were obtained by Wojdyło et al. in [16] in which currants from conventional cultivation contained more total flavonoids $(4.10 \mathrm{mg} / 100 \mathrm{~g} \mathrm{d.m}$.) than organic currants ( $3.99 \mathrm{mg} / 100 \mathrm{~g} \mathrm{d.m.)}$, and there was observed statistical significance in the content of flavonoids for individual varieties. Moreover, the 'Ben Alder' variety can be characterized by the highest concentration of these compounds.

\subsection{Anthocyanins Content}

Anthocyanins are the most important and numerous group of flavonoids contained in blackcurrants [17]. Wojdyło et al. [16] showed that, depending on the variety and cultivation method (organic, conventional), the total content of anthocyanins in fruit was from 104.45 to $156.83 \mathrm{mg} / 100 \mathrm{~g}$ for the varieties grown organically, and from 101.24 to $138.22 \mathrm{mg} / 100 \mathrm{~g}$ for the varieties grown conventionally. The main anthocyanins for Ribes nigrum L., located in its skin and responsible for the color of the fruit, are derivatives of dolphinidine and cyanidine, namely, glucoside-3-O-cyanidine, rutinoside-3-O-cyanidine, glucoside-3-Odelfinidine, and rutinoside-3-O-delphinidine. They may represent from $60 \%$ to $85 \%$ of the total phenolic compound content $[16,18]$. Additionally, their content in currants may vary depending on genetic predisposition, variety, conditions and method of cultivation, weather conditions during development, harvest period, methods of fruit processing and storage [19]. Anthocyanins have a high pro-health value associated with antioxidant, antiinflammatory, antimicrobial and anti-cancer-generative effects and prevent vision problems associated with fatigue or reduced visual acuity [17]. In addition, they contribute to risk reduction of atherosclerosis by affecting vasodilation and platelet aggregation [20]. Reports have shown that they display the ability to reduce total cholesterol and, like other phenolic compounds, possess the ability to scavenge free radicals, chelate metals and reduce lipid oxidation [21].

Cyanidin and delphinidin glycosides (3-O-glucoside and 3-O-rutinoside) make up $97 \%$ of all anthocyanins in blackcurrant fruit [22]. The mean total anthocyanin content (Table 4) in organic currants is $167.96 \mathrm{mg} / 100 \mathrm{~g}$ f.w., which is much higher than those from the conventional system at $146.72 \mathrm{mg} / 100 \mathrm{~g}$ f.w. The study showed that the way currants were grown significantly influenced the content of anthocyanins in the fruit-significantly higher for organic cultivation. Similar results were obtained by Wojdyło et al. [16], where organic currants contained substantially more anthocyanins (127.22 mg/100 g f.w.) than conventional currants ( $116.24 \mathrm{mg} / 100 \mathrm{~g}$ f.w.). The fruits also significantly differ statistically from one variety to another. The highest concentration of these compounds is characteristic of the 'Ben Alder' variety (174.41 mg/100 g f.w.) and smallest for the 'Tiben' variety (146.13 mg/100 g f.w.). On the other hand, Nour et al. [8] examined the anthocyanin content of eight currant varieties from Romania ('Abanos', 'Blackdown', 'Bogatar', 'Deea', 'Record', 'Ronix', 'Tenah Tinker'); their results indicated that the richest berries were those from the cultivar 'Record' (287.78 mg/100 g f.w.), and the lowest content of anthocyanins was found in 'Ronix' (116.17 mg/100 g f.w.). Mattila et al. [10] determined the anthocyanin content of 32 currant varieties available in Finland. Kikas et al. [23] determined high contents of delphinidin-3-O-rutinoside, the concentration of which was the highest among the anthocyanins tested. Kikas et al. [23] showed that the delphinidin-3-O-rutinoside content was dramatically higher in fruits of cultivars 'Tiben' and 'Ben Alder' (179 mg/100 g f.w. and $218 \mathrm{mg} / 100 \mathrm{~g}$ f.w.), compared to 'Titania' (129 mg/100 g f.w.), while our study determined that delphinidin-3-O-rutinosides content in cultivars 'Tiben', 'Ben Alder' and 'Titania' was $78.64 \mathrm{mg} / 100 \mathrm{~g}$ f.w., $101.38 \mathrm{mg} / 100 \mathrm{~g}$ f.w. and $107.74 \mathrm{mg} / 100 \mathrm{~g}$ f.w., respectively. Blackcurrant fruits with high contents of individual anthocyanins may have great potential in food products that are stored at low temperatures for long periods of time [24]. As mentioned by Kikas et al. [23], cyanidin-3-O-rutinoside ('Tiben'—93 mg/100 g f.w., 'Ben Alder'- 
$19.9 \mathrm{mg} / 100 \mathrm{~g}$ fw. and 'Titania' $-18 \mathrm{mg} / 100 \mathrm{~g}$ f.w.) and cyanidin-3-O-rutinoside ('Tiben'$7.29 \mathrm{mg} / 100 \mathrm{~g}$ f.w., 'Ben Alder' $-7.98 \mathrm{mg} / 100 \mathrm{~g}$ f.w. and 'Titania' $-8.12 \mathrm{mg} / 100 \mathrm{~g}$ f.w.) concentrations were higher than those presented in this study. The listed varieties contain a high level of anthocyanins, which may play a crucial role in terms of food preservation and thermal processing. Allwood et al. [25] and Woźnicki et al. [21] showed that high temperatures during the ripening period of currant fruits reduced the anthocyanin content. In addition, researchers observed the effect of flavonoid content reduction, mainly anthocyanins, when growing crops under a glass cover. Tian et al. [21] studied fruits from Lithuania, Latvia, Poland, Finland and Scotland, and found a general variation in the concentrations of various phenolic acid derivatives, even after more than five years of cultivation in the same geographical location and climatic conditions of the studied varieties. Vagiri et al. [26] and Krüger et al. [27] studies also showed that the content of organic acids, sugars and phenolic acid derivatives in blackcurrants is strongly correlated with the year of growth, which is caused by different weather conditions during fruit development.

\subsection{Vitamin C Content}

Among berries, the blackcurrant possesses the greatest vitamin $C$ content, ranging from 120 to $280 \mathrm{mg} / 100 \mathrm{~g}$ f.w., depending on the place of cultivation and variety. In Poland, wild rose fruits are the only plants that are superior to blackcurrant in terms of vitamin $C$ content $[2,8,27]$. Vitamin $C$ is very sensitive in comparison to other vitamins, and at the same time, is the least durable upon exposure to oxygen, $\mathrm{UV}$ radiation, $\mathrm{pH}$ or heavy metal ions, and is highly sensitive to damage by temperature and the time of exposure of the factors mentioned above [28]. Therefore, optimal antioxidant properties are found in the raw form. However, due to their low shelf life and the fact that they are a seasonal fruit, blackcurrants are usually eaten in processed form. It is worth mentioning that despite the processing and decreasing of antioxidant properties, blackcurrant preserves are still one of the best sources of antioxidants [16]. The average vitamin C content in blackcurrant fruits from the organic cultivation system is significantly higher, $138.85 \mathrm{mg} / 100 \mathrm{~g}$ f.w., than those from the conventional cultivation system, $128.68 \mathrm{mg} / 100 \mathrm{~g}$ f.w. The results obtained by Milivojević et al. [29] confirmed that blackcurrant fruits are the richest source of vitamin $\mathrm{C}$ among all berries. Their results achieving the highest value in 'Malling Juel' (141.4 mg/100 g f.w.), followed by 'Ben Sarek' (132.6 mg/100 g f.w.). In order to analyze the content of this compound in more detail, it is necessary to examine fruits that are developed under similar, or preferably identical, conditions of the external environment. Sasnauskas et al. [15] determined vitamin C content by evaluating varieties of currants cultivated in a conventional system at an average level of $109.75 \mathrm{mg} / 100 \mathrm{~g}$ of f.w. Kikas et al. [23] found no correlation between organic vs. conventional farming system for 'Ben Adler' and 'Titania' varieties, where the average vitamin C content for the conventional system was $188 \mathrm{mg} / 100 \mathrm{~g}$ f.w. and $103 \mathrm{~g} / 100 \mathrm{~g}$ f.w. for 'Titania', and in the organic system, $88 \mathrm{mg} / 100 \mathrm{~g}$ f.w. and $107 \mathrm{mg} / 100 \mathrm{~g}$ f.w. The authors noted that the cultivar 'Titania' was characterized by the lowest vitamin C content of all assessed cultivars (apart from the above-mentioned ones, in addition to 'Ben Lomond', 'Pamyati Vavilova', 'Intercontinental', 'Karri', 'Askar' and 'Mairi')—regardless of the year of cultivation and production system. Woźnicki et al. [30] showed negative correlation between the content of phenolic compounds and insolation in June and July. Temperature and sunshine in late spring and summer were also negatively correlated with the concentration of vitamin C, while rainfall in summer was strongly positively correlated with the concentration of this vitamin. These results show that the most favorable conditions for obtaining blackcurrant fruits with a high content of phenolic compounds, anthocyanins and vitamin $C$ are those with cool temperatures and heavy rainfall.

PCA displays a strong correlation for the cultivation system and currant varieties. Overall, $69.3 \%$ can be explained by PC1 and PC2 (Figure 4). The degree of dependence between blackcurrants from organic cultivation and factors, such as dry matter, total phenolic acids, chlorogenic acid, ferulic acid, myricetin, delphinidin-3-O-glucoside, cyanidin-3-O- 
glucoside, cyanidin-3-O-rutinoside and delphinidin-3-O-rutinoside compounds content, are particularly important. Researchers showed significant differences in the concentration of anthocyanins depending on the variety; their average content in fruit was $467 \mathrm{mg} / 100 \mathrm{~g}$ f.w. PCA showed a strong dependence toward the cultivation system and currant varieties.

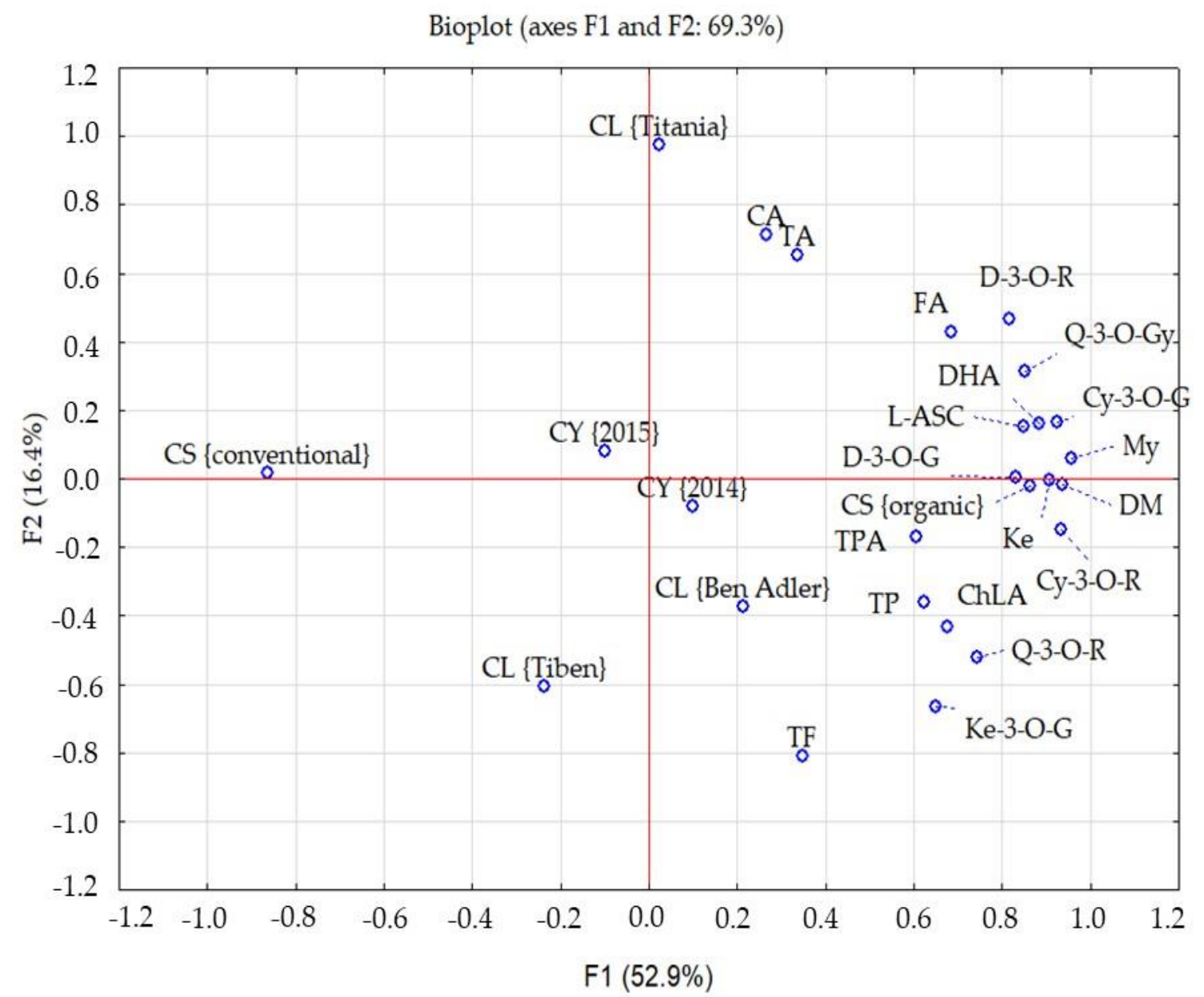

Figure 4. PCA analysis showing the relationship between the chemical composition-total polyphenols (TP), total phenolic acids (TPA), chlorogenic acid (ChLA), caffeic acid (CA), quercetin-3-O-glycoside (Q-3-O-Gy), ferulic acid (FA), total flavonoids (TF), kaempferol-3-O-glycoside (Ke-3-O-G), quercetin-3-O-rutinoside (Q-3-O-R), myricetin (My), kaempferol (Ke), total anthocyanins (TA), quercetin-3-O-glucoside (Q-3-O-G), cyanidin-3-O-rutinoside (Cy-3-O-R), delphinidin-3-Orutinoside (D-3-O-R), cyanidin-3-O-glycoside (Cy-3-O-G) and delphinidin-3-O-glucoside (D-3-O-G), in to experimental cultivation year (CY), cultivar (CL) and agronomic system (AS).

\subsection{The Practical Applications and Future Research Perspectives and Challenges}

Over $90 \%$ of the world's blackcurrants are cultivated in Europe, mainly in Poland. Worldwide blackcurrant production is around 180,000 tonnes, of which around three quarters are used for the production of concentrated juices and nectars. Three-quarters of the yield is processed into concentrated juice, while the rest of the production is used for fresh fruit and frozen fruit, and blackcurrant extracts. Data [31] show that blackcurrant production is stable, with a noticeable tendency to growth in organic production, which is increasing in European countries. Consumption of $100 \mathrm{~g}$ of blackcurrant daily may have beneficial health effects, i.e., protective antioxidant/anti-inflammatory cellular events that facilitate exercise recovery [32].

There is a large group of local, traditional blackcurrant cultivars that are less popular than commercial ones. In order to increase biodiversity, it is recommended to protect and popularize traditional and local cultivars. The selection of blackcurrant cultivars are 
aimed at a high content of bioactive compounds with a low content of contamination and pesticide residues. The review of the literature shows that black currants of various cultivars were sporadically tested; therefore, it is advisable to conduct tests related to the determination of the chemical composition, including the content of polyphenolic compounds. Moreover, the literature data indicate that their content can be significantly modulated by the cultivation system. In the light of the above, it seems appropriate to compare the chemical composition of the blackcurrant fruit with regard to organic and conventional cultivation.

\section{Conclusions}

Blackcurrants are a significant source of phenolic compounds and vitamin C. Our study shows a relationship between the cultivation system (organic vs. conventional) and currant cultivars, as well as the content of dry matter, vitamin C, and polyphenols, including anthocyanins. This study with the two-year observation shows that the results are stabilizing year after year and that they are not a loophole. Moreover, each time, they are in the same places of cultivation with specific agrotechnical conditions, which were monitored every day during the period of April-October for 2 years in both farms. The obtained results showed that organic blackcurrant fruits contain significantly more vitamin C (9.4 mg/100 g f.w.), total polyphenols (189.2 mg/100 g f.w.), total phenolic acids (10.3 mg/100 $\mathrm{g}$ f.w.), total flavonoids (178.8 mg/100 $\mathrm{g}$ f.w.), as well anthocyanins (167.9 mg/100 g f.w.), compared to conventional ones. Significant cultivar and cultivation year effects on the concentration of the measured polyphenols, with strong interactions between the two factors, were also identified. Higher concentrations of ferulic acid, quercetin-3-O-rutinoside, chlorogenic acid and quercetin-3-O-glucoside were identified among phenolic acids. Most of the studied compounds of polyphenols showed a significantly higher content in the blackcurrants from organic farming. Anthocyanins were found to be the predominant components consisting of delphinidin-3-O-rutinoside (major for both cultivars and agronomic system) and cyanidin (minor) of rutinoside and glucoside. Anthocyanins (except delphinidin-3-O-glucoside) had a significantly higher content in the blackcurrant from the organic agronomic system. Vitamin C levels varied widely between cultivars ('Ben Adler' had the highest level) and cultivation year. Consumers are searching for high quality and health-promoting foods; the bioactive ingredients found in blackcurrants can help maintain health, among others, through antioxidant properties of vitamin $C$ and phenolic acids. The results obtained can be valuable to consumers who are the main users of currants. Food producers should be encouraged to use currants, including organic ones, as a raw material for the production of functional food. We should strive to increase consumption of blackcurrants and encourage consumers to include this valuable fruit in their diet. We believe that the obtained results are interesting and allow us to clearly indicate that organic seasoning is associated with higher contents of bioactive compounds, which may be one of the arguments for promoting both currants and this method of cultivation among consumers.

Supplementary Materials: The following are available online at https:/ /www.mdpi.com/article/10 .3390/app11115113/s1, Figure S2A. Standard curves for all polyphenols identified in experiment in blackcurrant experiment, Figure S3A. Standard curves for all anthocyanins identified in experiment in blackcurrant experiment.

Author Contributions: Conceptualization. J.R.-J., E.H.; methodology. A.P.; E.H.; software. J.R.-J.; validation. J.R.-J.; A.P.; E.H.; formal analysis. J.R.-J.; E.H.; investigation. A.P.; E.H.; resources. A.P.; E.H.; data curation. E.H.; writing-original draft preparation. J.R.-J.; A.P.; E.H.; visualization. J.R.-J.; A.P.; E.H.; supervision. E.H.; project administration. E.H. All authors have read and agreed to the published version of the manuscript.

Funding: The study was funded by the Polish Ministry of Education and Science with funds of the Institute of Human Nutrition Sciences, Warsaw University of Life Sciences (WULS), for scientific research. 


\section{Institutional Review Board Statement: Not Applicable. \\ Informed Consent Statement: Not Applicable.}

Data Availability Statement: Data will be made available upon reasonable request by authors Alicja Ponder and Ewelina Hallmann.

Acknowledgments: This paper has been published under the support of Polish Ministry of Higher Education within founds of Institute of Human Nutrition Sciences. Warsaw University of Life Sciences (WULS) for scientific research.

Conflicts of Interest: The authors declare no conflict of interest.

\section{References}

1. Durazzo, A.; D'Addezio, L.; Camilli, E.; Piccinelli, R.; Turrini, A.; Marletta, L.; Marconi, S.; Lucarini, M.; Lisciani, S.; Gabrielli, P.; et al. From Plant Compounds to Botanicals and Back: A Current Snapshot. Molecules 2018, 23, 1844. [CrossRef] [PubMed]

2. Cavanagh, H.M.; Hipwell, M.; Wilkinson, J.M. Antibacterial activity of berry fruits used for culinary purposes. J. Med. Food 2003, 6, 57-61. [CrossRef]

3. Gopalan, A.; Reuben, S.C.; Ahmed, S.; Darvesh, A.S.; Hohmann, J.; Bishayee, A. The health benefits of blackcurrants. Food Funct. 2012, 3, 795-809. [CrossRef]

4. Tomisawa, T.; Nanashima, N.; Kitajima, M.; Mikami, K.; Takamagi, S.; Maeda, H.; Horie, K.; Lai, F.; Osanai, T. Efects of Blackcurrant Anthocyanin on Endothelial Function and Peripheral Temperature in Young Smokers. Molecules 2019, $24,4295$. [CrossRef] [PubMed]

5. Koch, W. Dietary Polyphenols-Important Non-Nutrients in the Prevention of Chronic Noncommunicable Diseases. A Systematic Review. Nutrients 2019, 11, 1039. [CrossRef] [PubMed]

6. Djordjević, B.; Rakonjac, V.; Fotirić-Akšić, M.; Šavikin, K.; Vulić, T. Pomological and biochemical characterization of European currant berry (Ribes sp.) cultivars. Sci. Hortic. 2014, 65, 156-162. [CrossRef]

7. Durazzo, A. Study approach of antioxidant properties in foods: Update and considerations. Foods 2017, 6, 17. [CrossRef]

8. Nour, V.; Trandafir, I.; Ionica, M.E. Ascorbic acid, anthocyanins, organic acids and mineral content of some black and red currant cultivars. Fruits 2011, 66, 353-362. [CrossRef]

9. Heinonen, M. Antioxidant activity and antimicrobial effect of berry phenolics-A Finnish perspective. Mol. Nutr. Food Res. 2007, 51, 684-691. [CrossRef]

10. Mattila, P.H.; Hellström, J.; Karhu, S.; Pihlava, J.M.; Veteläinen, M. High variability in flavonoid contents and composition between different North-European currant (Ribes spp.) varieties. Food Chem. 2016, 204, 14-20. [CrossRef]

11. European Commission, European Green Deal: Commission Presents Actions To Boost Organic Production. 25.03.2021. Available online: https: / / ec.europa.eu/commission/presscorner/detail/en/IP_21_1275 (accessed on 19 May 2021).

12. Polish Norm PN-R-04013:1988. The Estimation of Dry Matter in Fruits and Vegetables; Polish Standard Committee: Warsaw, Poland, 1988.

13. Ponder, A.; Hallmann, E. The effects of organic and conventional farm management and harvest time on the polyphenol content in different raspberry cultivars. Food Chem. 2019, 302, 125295. [CrossRef] [PubMed]

14. Ponder, A.; Hallmann, E. The nutritional value and vitamin C content of different raspberry cultivars from organic and conventional production. J. Food Compos. Anal. 2020, 87, 1-14. [CrossRef]

15. Sasnauskas, A.; Trajkovski, V.; Strautina, S.; Tikhonova, O.; Šikšnianas, T.; Rubinskiene, M.; Viškelis, P.; Lanauskas, P.; Valiuškaitè, A.; Rugienius, R.; et al. Evaluation of blackcurrant cultivars and perspective hybrids in Lithuania. Agron. Res. 2009, 7, 737-743.

16. Wojdyło, A.; Oszmiański, J.; Milczarek, M.; Wietrzyk, J. Phenolic profile, antioxidant and antiproliferative activity of black and red currants (Ribes spp.) from organic and conventional cultivation. Int. J. Food Sci. Technol. 2013, 48, 715-726.

17. Chen, X.-Y.; Huang, I.-M.; Hwang, L.S.; Ho, C.-T.; Li, S.; Lo, C.-Y. Antocyanins in Blackcurrant effectively prevent the formation of advanced glycation and products by trapping methylglyoxal. J. Funct. Foods 2014, 8, 259-268. [CrossRef]

18. Šavikin, K.; Mikulič-Petkovšek, M.; Djordjević, B.; Zdunić, G.; Jankowić, T.; Djurović, D.; Veberič, R. Influence of shading net on polyphenol profile and radical scavenging activity in different varieties of black currant berries. Sci. Hortic. 2013, 160, 20-28. [CrossRef]

19. Zdunić, G.; Šavikin, K.; Pljevljakušić, D.; Djordjević, B. Black (Ribes nigrum L.) and red currant (Ribes rubrum L.) Cultivars. In Nutritional Composition of Fruit Cultivars; Simmonds, M., Preedy, V.R., Eds.; Academic Press: London, UK, 2016; pp. 101-126.

20. Reis, J.F.; Monteiro, V.V.; de Souza Gomes, R.; do Carmo, M.M.; da Costa, G.V.; Ribera, P.C.; Monteiro, M.C. Action mechanism and cardiovascular effect of anthocyanins: A systematic review of animal and human studies. J. Transl. Med. 2016, 14, 1-16. [CrossRef]

21. Woźnicki, T.L.; Heide, O.M.; Sønsteby, A.; Wold, A.-B.; Remberg, S.F. Effects of controlled post-flowering temperaturę and daylength on chemical composition of four black currant (Ribes nigrum L.) cultivars of contrasting origin. Sci. Hortic. 2015, 19, 627-636. [CrossRef]

22. Tian, Y.; Laaksonen, O.; Haikonen, H.; Vanag, A.; Ejaz, H.; Linderborg, K.; Karhu, S.; Yang, B. Compositional Diversity among Blackcurrant (Ribes nigrum) Cultivars Originating from European Countries. J. Agric. Food Chem. 2019, 67, 5621-5633. [CrossRef] 
23. Kikas, A.; Rätsep, R.; Kaldmäe, H.; Aluvee, A.; Libek, A.-V. Comparison of Polyphenols and Anthocyanin Content of Different Blackcurrant (Ribes nigrum L.) Cultivars at the Polli Horticultural Research Centre in Estonia. Agron. Res. 2020, 18, $2715-2726$. [CrossRef]

24. Rubinskiene, M.; Viskelis, P.; Jasutiene, I.; Viskeliene, R.; Bobinas, C. Impact of various factors on the composition and stability of black currant anthocyanins. Food Res. Int. 2005, 38, 867-871. [CrossRef]

25. Allwood, J.W.; Woznicki, T.L.; Xu, Y.; Foito, A.; Aaby, K.; Sungurtas, J.; Freitag, S.; Goodacre, R.; Stewart, D.; Remberg, S.F.; et al. Application of HPLC-PDA-MS metabolite profiling to investigate the effect of growth temperature and day length on blackcurrant fruit. Metab. Off. J. Metab. Soc. 2019, 15, 12. [CrossRef]

26. Vagiri, M.; Ekholm, A.; Johansson, E.; Andersson, S.C.; Rumpunen, K. Major phenolic compounds in black currant (Ribes nigrum L.) buds: Variation due to genotype, ontogenetic stage and location. Food Sci. Technol. 2015, 63, 1274-1280. [CrossRef]

27. Krüger, E.; Dietrich, H.; Hey, M.; Patz, C.D. Effects of cultivar, yield, berry weight, temperature, and ripening stage on bioactive compounds of black currants. J. Appl. Bot. Food Qual. 2011, 84, 40-46.

28. Sheraz, M.; Khan, M.; Ahmed, S.; Kazi, S.; Ahmad, I. Stability and Stabilization of Ascorbic Acid. Househ. Pers. Care Today 2015, $10,20-25$.

29. Milivojević, J.; Bogdanovic, J.; Maksimović, V. Phenolic compounds and vitamin C as sources of antioxidant activity in black currant fruit (Ribes nigrum L.). Acta Agric. Serbica 2010, 29, 3-10.

30. Woznicki, T.L.; Heide, O.M.; Sønsteby, A.; Wold, A.-B.; Remberg, S.F. Yield and fruit quality of black currant (Ribes nigrum L.) are favoured by precipitation and cool summer conditions. Acta Agric. Scand. 2015, 65, 702-712. [CrossRef]

31. Blackcurrant Foundation. Available online: https://www.blackcurrant-iba.com/wp-content/uploads/2019/10/Global-BCProduction-2009-2018.pdf (accessed on 19 May 2021).

32. Hurst, R.D.; Lyall, K.A.; Wells, R.W.; Sawyer, G.M.; Lomiwes, D.; Ngametua, N.; Hurst, S.M. Daily Consumption of an Anthocyanin-Rich Extract Made from New Zealand Blackcurrants for 5 Weeks Supports Exercise Recovery Through the Management of Oxidative Stress and Inflammation: A Randomized Placebo Controlled Pilot Study. Front. Nutr. 2020, 7, 16. [CrossRef] [PubMed] 